\title{
Monitoring of Omega -3 level as a Marker of Oxidative Stress in Rats Exposed to Microwave Radiation
}

\author{
Ghada M. Nabil \\ Laboratory of Biophysics,Biochemistry Department, National \\ Research Center, Cairo Egypt.
} \begin{abstract}
HIS STUDY aimed to investigate firstly, the oxidative stress and
erythrocyte hemolysis due to the effect of exposure to $2450 \mathrm{MHz}$
T continuous microwave (MW), which is the carrier of signals emitted by cellular phones. Secondly to evaluate the possible protective role of omega-3 supplementation. Before exposure to microwaves, male rats were randomly divided into four groups, the first group was considered as control, the second group was exposed to microwave at frequency $2450 \mathrm{MHz}$ alone, the third group was supplemented by omega $-3(40 \mathrm{mg} / \mathrm{kg})$ and the fourth group was exposed to $\mathrm{MW}$ but supplemented by omega $-3(40 \mathrm{mg} / \mathrm{kg})$ before irradiation. The level of Malondialdehyde (MDA), an index of lipid peroxidation (LPO), was estimated and used as a marker of oxidative stress. Superoxide dismutase (SOD), catalase (CAT), and glutathione peroxidase (GSH$\mathrm{Px}$ ) activities were expressed to evaluate the changes of antioxidant status. Also erythrocyte osmofragility test was assessed to determine rate by which red blood cells will undergo hemolysis. The level of malondialdehyde significantly elevated and the levels of some antioxidative enzymes significantly decreased, in addition the erythrocyte hemolysis rate increased in the MW group (second group) as compared to the control group. Oral administration of omega -3 (OT) exhibited marked amelioration of LPO, antioxidative enzymes, and rate of hemolysis which returned to normal values during the course of OT treatment. It could be concluded that OT has an obvious antioxidant effect that may be able to compensate MW-induced oxidative changes in the blood tissue by enhancing the antioxidant defense system.
\end{abstract}

Key words: Microwave, Omega-3, Antioxidant, Erythrocyte

The use of a high quality omega-3 as antioxidant is critical to the immune system and reduction of inflammation, especially chronic inflammation. Exposure to radioactive materials from a nuclear accident puts tremendous stress on the whole body, and omega-3 essential fatty acids provide the body with a way of dealing with the effects of stress and oxidation by strengthening the cell membranes throughout the whole body. Microwave radiation is a type of nonionizing electromagnetic radiation present in the environment, and is a potential threat to human health. Today, non-ionizing radiation has increasingly been used in industry, commerce, medicine, and for private purposes, especially in mobile telephone usage. Although average exposure levels are low compared to exposure limits, there is a growing public concern about the potential hazard of exposure to these frequencies for human health ${ }^{(1-3)}$. 
It is well known that low frequency microwaves include the more harmful fractions. Yet the design of new high frequency machines has also increased the harmful fractions. Reports of hypertension, headaches, memory failure, brain damage, dementia, abortion and breast cancer have been related to exposure to strong microwaves ${ }^{(4)}$. High frequency microwaves increase the temperature of human tissue, which is especially harmful for reproduction and fertilization and to blood forming cells ${ }^{(5,6)}$

It is also known that microwaves generate free radicals that accelerate the aging process in human tissue, and promote adult chronic diseases and cancer, Waters $e t a l^{(7)}$ reported that microwaves generate harmful oxygen radicals that lead to DNA damage. Moustafa et $\mathrm{l}^{(8)}$. also observed that $2.45 \mathrm{GHz}$ microwaves produce an increase in lipid peroxide ${ }^{(8)}$. With the introduction of cellular telephones, even more public attention has been drawn to the possible bioeffects of low- level exposure to radiofrequency and microwave radiation (rf/MW). Many epidemiological studies have addressed the possible links between exposure to rf/MW fields and excess risk for cancer ${ }^{(9,10)}$.

A part of a larger investigation designed to determine biological indicators of microwave radiation after whole- body exposure of rats were the studies of (Torsic et al ${ }^{(11)}$ and Garai Vrhovac et al. ${ }^{(12)}$ described the incidence of cytogenetic damage as assessed by the micronucleus assay, and incidence of DNA damage as assessed by comet assay.

Recent studies reported abaut the potent antioxidant properties, in both lipid peroxidation ${ }^{(13)}$ and oxidative cell death ${ }^{(14)}$. Also omega -3 (OT) has multiple health benefits due to antioxidant/antiradical activity due to a high degree of oxygen free radical scavenging potential ${ }^{(15)}$.

In addition to antioxidant/antiradical of (OT) activity, were shown to possess many biological properties including the inhibition of DNA damage ${ }^{(16)}$, prevent chromosomal damage in human lymphoblastoid cells ${ }^{(17)}$, prevent oxidative injury by modulating the expression of antioxidant enzyme systems ${ }^{(13)}$, modulation of lipid metabolism and inhibition of low-density lipoprotein oxidation ${ }^{(12-16)}$.

The aim of this study was to test the hypothesis that the exposure to 2450 $\mathrm{MHz}$ microwave irradiation induces a disturbance in enzyme activities of antioxidative system and erythrocyte hemolysis, and to investigate the protective effect of omega -3 in rats.

\section{Materials and Methods}

\section{Animal Model}

Adult male Wistar rats (10 weeks old and average body weight $250 \mathrm{~g}$ ) obtained from the Laboratory Animal Production Unit of National Research Center were used in the study. The experimental group of animals $(N=48)$ were 
kept in an environment of controlled temperature $\left(24-26^{\circ} \mathrm{C}\right)$, humidity $(55-$ $60 \%$ ), and received standard laboratory food and water adlibitum, with alternating $12 \mathrm{hr}$ light and dark cycles. They were under responsibility of veterinary in compliance with the Guide for the Care and Use of Laboratory Animals for Scientific Purposes. Animals were kept for 1 month before the start of the experiment.

\section{Microwave exposure system}

The experimental groups were exposed to $2450 \mathrm{MHz}$ continuous waves MW for $1 \mathrm{hr}$ daily for 30 days and every day at the same hour. Animals were placed in individual Plexiglas cages and exposed to the MW oven (550 Watt, $2450 \mathrm{MHz}$ Imperial V- 8505T Model). The device was modified to supply nonthermal conditions by water- cooled coils. Thus, the experiments were carried out at $37^{\circ} \mathrm{C}\left( \pm 1{ }^{\circ} \mathrm{C}\right)$. The power density of the field within the individual cages was measured with an EM Radiation Monitor, (Wandel \& Golterman GmbH \& Co., Germany) at 'average mode' option. Mean total-body specific absorption rates were estimated according to standard procedures $(2 \mathrm{~W} / \mathrm{kg})$ and average power density $\left(0.251 \mathrm{~mW} / \mathrm{cm}^{2}\right)$. ${ }^{(18)}$

\section{Experimental design}

The animals were classified into four groups, 12 rats in each:

Group 1: Control group. Group 2: Microwave irradiated group. Group 3: Rats were orally supplemented with Omega 3 (fish oil, EPA/DHA 30\%) by means of stomach needle at dose $40 \mathrm{mg} / \mathrm{kg}$ body weight for thirty days. Group 4: Rats were orally supplemented with Omega 3 (fish oil, EPA/DHA 30\% and wheat germ oil ) by means of stomach needle at dose $40 \mathrm{mg} / \mathrm{kg}$ body weight for thirty days before MW irradiation.

\section{Blood sampling}

Animals were anesthetized and whole blood samples were collected by cardiac puncture at the end of experimental period in heparinised tubes containing lithium heparin as anticoagulant. After collection, blood was divided into many samples according to experimental groups.

\section{Analytical procedures}

Blood lipid peroxidation was measured as the amount of malondialdehyde (MDA) formed, employing thiobarbituric acid as described by Yo shioka et $a l .{ }^{(19)}$ using a spectrophotometer (Shimadzu UV-1601, Japan). Activity of the antioxidant scavenger enzymes glutathione peroxidase (GSH-Px), Superoxide dismutase (SOD) and catalase (CAT) were measured spectrophotometrically according to the methods of Paglia et al. ${ }^{(20)}$, Klamt et al. ${ }^{(21)}$ and Aebi ${ }^{(22)}$, respectively.

Osmofragility test was carried out within two hours of collection of blood. The osmotic fragility of the membrane can be measured by placing the red blood cells in hypotonic salt solutions, the osmotic pressure exerted by the diffusion of water into the cells, makes them first swell and then hemolyse. The 
osmotic fragility measures the capacity of the cells to withstand hypotonicity and resist hemolysis, which is determined by their volume to surface area ratio ${ }^{(23)}$. Red blood cells were added to varying concentrations of buffered sodium chloride solution $\mathrm{NaCl}$ buffered to $\mathrm{pH} 7.4$ and kept at $25^{\circ} \mathrm{C}$. The amount of hemolysis in each saline concentration was then determined by reading the absorbance of supernatant at $450 \mathrm{~nm}$ using a double beam UV/VIS spectrophotometer model-240 manufactured by shimadzue - Japan. This procedure was followed for the treatment of each blood sample collected from the animals

\section{Statistical analysis}

All the experimental data were expressed as the means \pm SE. Each experiment was carried out at least three times. Statistical significances of differences between two groups were determined using Student's t-test. All P values were two-sided, and $\mathrm{P}<0.05$ was considered statistically significant.

\section{Results}

The data of the present study revealed that exposure to frequency 2450 $\mathrm{MHz}, 0.25 \mathrm{~mW} / \mathrm{cm}^{2}$ continuous waves $\mathrm{MW}$ for $1 \mathrm{hr}$ daily for 30 days induced significant decrease in antioxidant enzymes activities of glutathione peroxidase $($ GSH-Px) $(\mathrm{P}<0.001)$, catalase $(\mathrm{CAT}) \quad(\mathrm{P}<0.05)$ and superoxide dismutase (SOD) $(\mathrm{P}<0.001)$ when compared to control group as illustrated in Table 1. Such decrease was accompanied with significant increase in malondialdehyde level which indicates lipid peroxidation degree (MDA) $(\mathrm{P}<0.001)$, (Fig. 1).Regarding the data recorded in Table 1 , on comparing with microwave irradiated group, it was observed that administration of omega 3 protector either prior to MW radiation exposure or to normal groups significantly increased the activities of (GSH-Px) $(\mathrm{P}<0.05, \mathrm{P}<0.001),(\mathrm{CAT})(\mathrm{P}<0.05, \mathrm{P}<0.05)$ and (SOD) $(\mathrm{P}<0.001, \mathrm{P}<0.001$, respectively. The data in Fig.1, revealed a significant decrease in the level of malondialdehyde on administration of omega-3 protector prior to MW radiation exposure $(\mathrm{P}<0.05)$ and OT group $(\mathrm{P}<$ 0.001 ) as compared with MW irradiated group.

TABLE 1. Effect of Omega 3 (OT) on glutathione peroxidase (GSH-Px), catalase (CAT) and superoxide dismutase (SOD) activities in normal and rats exposed to microwave (MW) radiation.

\begin{tabular}{|c|c|c|c|}
\hline Groups & GSH-Px U/ $\mathbf{m i n} / \mathbf{m l}$ & $\mathbf{C A T} \mathbf{\mu m o l} / \mathbf{m i n} / \mathbf{m l}$ & SOD $\mathbf{~ m o l} / \mathbf{m l}$ \\
\hline Control & $43.52 \pm 2.19$ & $9.81 \pm 1.08$ & $1.16 \pm 0.06$ \\
\hline MW Radiation & $29.91 \pm 3.01 \mathrm{a}$ & $4.12 \pm 0.72 \mathrm{a}$ & $0.48 \pm 0.02 \mathrm{a}$ \\
\hline OT protector & $49.60 \pm 4.71 \mathrm{~b}$ & $9.50 \pm 1.67 \mathrm{~b}$ & $1.02 \pm 0.05 \mathrm{~b}$ \\
\hline MW Radiation +OT & $40.11 \pm 2.03$ & $8.03 \pm 1.54 \mathrm{~b}$ & $0.74 \pm 0.03 \mathrm{a}, \mathrm{b}$ \\
\hline
\end{tabular}

Each value represent a mean of 12 rats $\pm \mathrm{SE}$

a significantly different from control group

$\mathrm{b}$ significantly different from MW irradiated group 


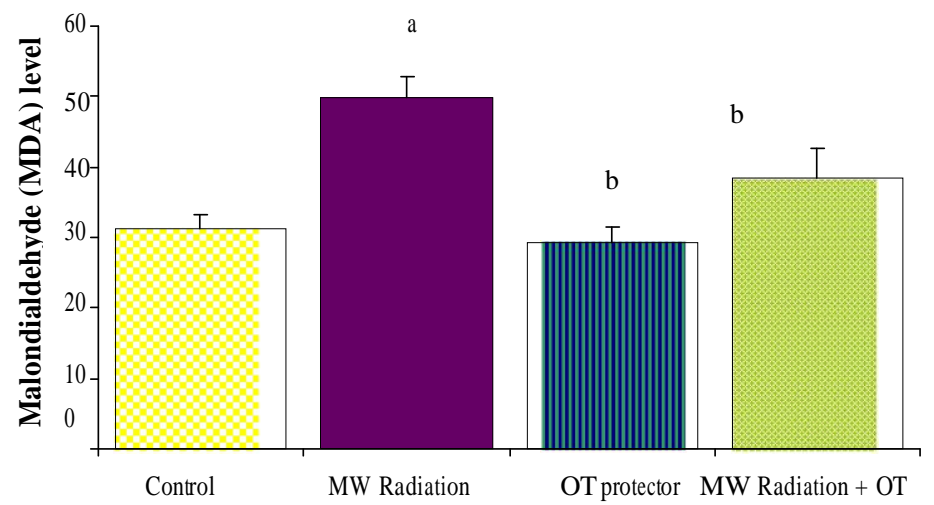

Fig.1. Effect of Omega 3 (OT) on malondialdehyde level (MDA) in rats exposed to microwave $(\mathrm{MW})$ radiation.

Data are represented as mean of 12 rats $\pm \mathrm{SE}$

asignificantly defferent from control group

${ }^{\mathrm{b}}$ significantly different from MW irradiated group

Figure. 2 showed the results of osmotic fragility measurements for the RBCs collected from animals of the different groups, where the percentage of hemolysed cells was plotted as a function of the concentration percentage of $\mathrm{NaCl}$. For analysis of these results, the curves were differentiated and plotted as a function of $\mathrm{NaCl}$ concentration percentage as shown in Fig. 3.

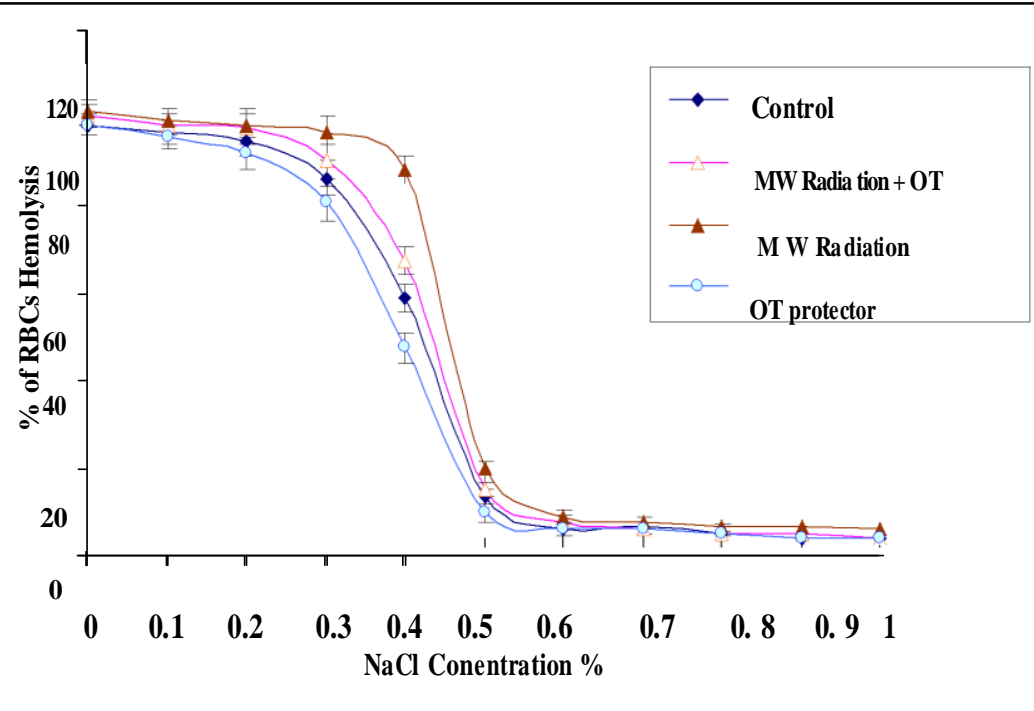

Fig. 2.Variation of the hemolysis percentage of the RBCs as a function of the surrounding $\mathrm{NaCl}$ concentration percentage in the saline medium for different sample groups of the study . 
As a result of this treatment each characteristic plot in Fig. 2 was represented by a peak in Fig. 3. From Fig.2 and 3, the mean corpuscular fragility (MCF) (the $\mathrm{NaCl}$ concentration at which $50 \%$ of RBCs are hemolyzed) and the maximum half width (Wh max), (indicates the elastic range given in Table 2 of the RBCs cellular membrane) were calculated.

TABLE 2. Red blood cells mean corpuscular fragility (MCF) calculated in $\mathrm{g} \% \mathrm{NaCl}$, and the corresponding maximum half width $\left(W_{h}\right.$ max $)$ for different groups

\begin{tabular}{|l|c|c|}
\hline & MCF $(\mathbf{g} \% \mathbf{~ N a C l})$ & $\mathbf{W h}_{\mathbf{h}} \mathbf{m a x}$ \\
\hline Control & $0.51 \pm 0.09$ & $0.173 \pm 0.042$ \\
\hline MW Radiation & $0.50 \pm 0.07$ & $0.112 \pm 0.040$ \\
\hline OT protector & $0.38 \pm 0.08$ & $0.198 \pm 0.026$ \\
\hline MW Radiation + protector & $0.42 \pm 0.12$ & $0.132 \pm 0.037$ \\
\hline
\end{tabular}

The results of osmotic fragility test revealed that exposure to microwave radiation caused shift to the right of the hemolysis curve indicating increase in the mean corpuscular fragility (MCF) as shown in Table 2 . The widths at half maximum of these differential plots represent the relative elastic limit of RBCs membrane. The increase of $\mathrm{Wh}_{\mathrm{h}} \max$ indicates the increase of cellular membrane elasticity. The results indicated that both RBCs membrane elasticity and permeability decreased due to exposure of the animals to MW radiation. Administration of Omega 3 ( OT) either to normal or pre-exposure to MW radiation improved the values of MCF and $\mathrm{Wh}$ max.

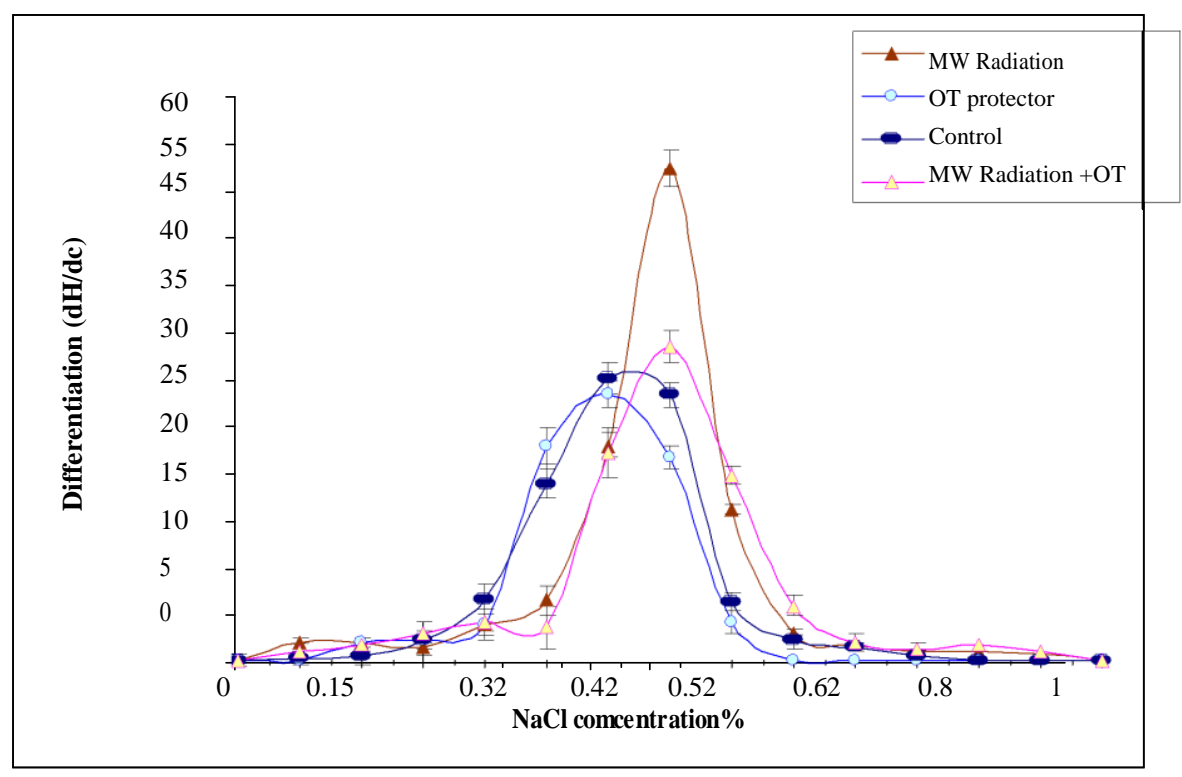

Fig. 3. Differentiation curves for different sample groups.

Egypt. J. Biophys. Biomed. Engng. Vol. 12 (2011) 


\section{Discussion}

The biological effects of non-thermal MWs are dependent on such physical parameters as frequency, intensity, polarization, and modulation (24-26). There is growing evidence that the effects of microwave irradiation are mediated by the formation of reactive oxygen species (ROS) and free radicals, which are highly reactive, removing hydrogen atoms from fatty acids, causing lipid peroxidation and consequently cell death. Stopczyk et al. ${ }^{(27)}$ and Mostafa et $a l^{(8)}$ studied the oxidation of lipid associated with depletion in antioxidant enzymes contents due to microwave irradiation. It was suggested that the oxidant / antioxidant disequilibrium due to oxidative stress is the main cause of excessive formation of peroxides as $\mathrm{MDA}^{(15)}$. In agreement with our lipid peroxidation and oxidative damage results, some previous studies suggested that UHF-EMF and microwave radiation might also increase free radicals formation, based on the assumption that reactive oxygen species (ROS) are implicated in several types of tissue injury ${ }^{(28-31)}$.

Some researchers were conducted to discuss potential health risk of microwave radiation due to oxidative stress ${ }^{(27,30,32)}$. The present study showed that exposure to MW with a frequency of $2450 \mathrm{MHz}$ had a significant effect on rat's red blood cells suggesting that ROS were generated under the experimental conditions applied. A significant increase was observed in MDA level and significant decrease in antioxidant activities in the exposed group. The change in activities of antioxidant enzymes with MDA levels may be regarded as an indicator of increased ROS production occurring during the exposure period and may reflect the pathological process of the exposure to microwave radiation. These continuously production of ROS are scavenged by SOD, GSH-Px and CAT. Under some circumstances, these endogenous antioxidative defenses are likely to be perturbed as a result of overproduction of oxygen radicals, inactivation of detoxification systems, consumption of antioxidants, and failure to adequately replenish antioxidants in tissue. It was demonstrated in numerous studies that ROS are directly involved in oxidative damage of cellular macromolecules such as lipids, proteins, and nucleic acids in tissues ${ }^{(29,33)}$.

Administration of OT significantly stimulated the reduced activities of SOD, GSH-Px and CAT in blood tissue over those measured in the MW-exposed and control groups. The potent efficancy of OT as antioxidant in suppressing lipid peroxidation was reported before ${ }^{(16,43)}$. It was found that the free radical scavenging capacity of OT is more effective than some vitamins ${ }^{(35)}$. OT showed potent antioxidant activity by trapping free radicals (hydroxyl, lipid free radicals, free iron molecules and lipid peroxides), delaying fat oxidation, inhibiting the major substance responsible for generating oxygen derived free radicals and reducing the concentration of hydrogen peroxide produced by the oxidative stress ${ }^{(17)}$. The antioxidant activity of omga 3 was evaluated by measuring it's capacity to scavenge hydrogen peroxide and to decrease the rate of peroxide formation, the antioxidant activity of omega 3 increased when the concentration increased ${ }^{(36)}$. So,the results were in agreement with previous researches. The ameliorated and the radiprotective effect of OT could be explained by its ability to trap harmful free 
radicals and consequently decrease their cytotoxic effect. The adverse effects of of $2.45 \mathrm{GHz}$ radiation $\left(0.25 \mathrm{~mW} / \mathrm{cm}^{2}\right)$ on the erythrocyte membrane were confirmed by measuring the $\mathrm{Hb}$ Osmofragility (expressed as the degree of hemolysis) after exposure to radiation and after reatment with. OT protector. Our results illustrated change in the RBCs osmotic fragility of exposed animals which reflects changes in the properties of RBCs membranes. It was reported by Savopol et al. ${ }^{(37)}$ that power levels, $2.45 \mathrm{GHz}$ irradiation induced significant $\mathrm{Hb}$ loss due to transient permeabilization of irradiated erythrocytes. The degree of hemolysis increased with increasing microwave power density.

Free radicals formed during microwave irradiation lead to a variety of membrane changes including lipid peroxidation, amino acid residue damage in membrane proteins and lipid-protein crosslinks Schon et al. ${ }^{(38)}$ and Kuchel et al. ${ }^{(39)}$ reported that modification in the physical condition of the proteins on the cell membrane leads to change in the permeability of the RBCs membrane. Some proteins on the cell membrane (ion channels) act as pores through which the liquid (water) bound to ions carried inside the cell. The applied radiation may cause a variation on the electrical charges distributed on the RBCs membrane. The rearrangement of the electrical charges may affect the ion channels proteins as a cause of unbalance in the ionic concentration, which may leads to changes in membrane structures and affect the cytoskeleton. The combined effects of free radicals on the red blood cell membrane and cytoskeleton may contribute to the leak of hemoglobin out of the cells. The hemolysis of the red blood cells reflects the loss of integrity of the cells, which leads to the liberation of intracellular hemoglobin ${ }^{(38,40)}$. The width at half maximum of the differential plot $\left(\mathrm{W}_{\mathrm{h}} \max \right)$ as shown in Fig. 3 and Table 2, represents the elastic limit of RBCs' membrane. The increase in $\mathrm{W}_{\mathrm{h}}$ max represents the increase in cellular membrane elasticity, so the elasticity of RBCs membrane decreased as a result of MW exposure.

Treatment by OT revised the erythrocyte membrane elasticity to its normal trend. It was reported that DHA supplementation could reduce the aggregation of platelets, increase the red blood cell, decrease blood viscosity and increase the fibrinolytic activity ${ }^{(41)}$. In addition, improving the oxygen carrying capacity of blood, and increase the strength and elasticity of blood vessel wall by binding with collagen. Omega 3 in general, in fish oil and wheat germ oil in particular are free of side effects, since they are used in cases of hyperlipoproteinaemia for example atherosclerosis, any excess are excreted via water or urine. OT is effective in preventing the oxidative stress associated with loss of membrane surface charge which maintains the erythrocyte membrane integrity and function ${ }^{(16)}$. According to the results obtained it could be concluded that omega 3 is acting in concert science as it has a perspective role as antioxidant. 


\section{References}

1. Breckenkamp, J. Berg G. and Blettner, M., Biological effects on human health due to radiofrequency/microwave exposure: a synopsis of cohort studies. Radiat. Environ. Biophys. 42 (3), 141-154 (2003).

2. ICNIRP Report., Epidemiology of health effects of radiofrequency. Environ. Health Perspect 112, 1741-1754 (2004).

3. Jauchem, J.R., Effects of low-level radio-frequency (3 kHz to $300 \mathrm{GHz})$ energy on human cardiovascular, reproductive, immune and other systems: a review of the recent literature. Int. J. Hyg. Environ. Health 211, 1-29 (2008)

4. Radovanobicic, J., Winterhalter, M., Jadric, R., Gornjakovic, S, Effects of microwave irradiation of biological systerm. Med. Arch. 48,101-4 (1994).

5. Trosic, I., Multinucleated giant cell appearance after whole body microwave irradiation of rats. Int. J. Hyg. Environ. Health. 204, 133-138 (2001).

6. Trosic, I., Busljeta, I. and Pavicic, I., Blood-forming system in rats after wholebody microwave exposure; reference to the lymphocytes. Toxicology Letters, 154, 125132, (2004).

7. Waters, D.J., Shen, S., Xu, H., Kengeri, S.S., Cooley, D.M., Chiang, E.C., Chen, Y., Schlittler, D., Oteham, C., Combs, JrG, F., Glickman, L.T., Morris, J.S. and Bostwick, D.G., Noninvasive prediction of prostatic DNA damage by oxidative stress challenge of peripheral blood lymphocytes. Cancer Epidemiol. Biomark. Prev, 16, 19061910 (2007).

8 . Moustafa, Y.M., Moustafa, R.M., Belacy, A., Abou-EI- Ela, S.H. and Ali, F.M., Effects of acute exposure to the radiofrequency fields of cellular phones on plasma lipid peroxide and antioxidase activities in human erythrocytes. J. Pharm. Biomed. Anal. 26, 605-8 (2001).

9. Tice, R.R., Hook, G.G., Doner, M., McRee, D.I. and Guy, A.W., Genotoxicity of radiofrequency signals. I. Investigation of DNA damage and micronuclei induction in cultured human blood cells. Bioelectromag. 23,113-126 (2002).

10. Vijayalaxmi O.G., Controversial cytogenetic observations in mammalian somatic cells exposed to radiofrequency radiation. Radiat. Res. 162, 481-496 (2004).

11. Trosic, I., Busljeta, I., Kasuba, V., Rozgaj, R., Micronucleus induction afterwhole body microwave irradiation of rats. Mutation Research 521, 73-79 (2002).

12. Garaj-Vrhovac, V., Gajski, G., Trosi, I. and Pavici, I.; Evaluation of basal DNA damage and oxidative stress in Wistar rat leukocytes after exposure to microwave radiation. Toxicology 259, 107-112 (2009).

13. Ariga, T., The antioxidant function, preventive action on disease and utilization of proanthocyanidins. Biofactors, 21, 197-201 (2004). 
14. Li, M.H., Jang, J.H., Sun, B. and Surh, Y.J. Protective effects of oligomers of grape seed polyphenols against beta-amyloid-induced oxidative cell death, Ann. NY. Acad. Sci. 1030, 317-329 (2004).

15. Heller, A.R., Rossler, S. and Litz, R., Omega-3 fatty acids improve the diagnosis related clinical outcome. Crit. Care Med. 34 (4), 972-979 (2006).

16. Simopoulos , A., The importance of the omega 6/omega 3 fatty acid ratio in cardiovascular disease and other chronic disease . Experimental Biology and Medicine, 6, 674-688 (2008).

17. Al- Gubory H.Kais, Mitochondria: Omega -3 in the route of mitochondrial reactive oxygen species. The International Journal of Biochemistry and Cell Biology http://dx.doi.org/10.1016/j.biocel.2012.06.003 (2012)

18. ICNIRP Guidelines, Guidelines for limiting exposure to time-varying electric, magnetic and electromagnetic fields (up to $300 \mathrm{GHz}$ ). Health Physics, 74, 494-522 (1998).

19. Yoshioka, T., Kawada, K., Shimada, T. and Mori, M., Lipid peroxidation in maternal and cord blood and protective mechanism against activated- oxygen toxicity in the blood. Am. J. Obstet. Gynecol. 135, 372-376 (1979).

20. Paglia, D.E. and Valentine, W.N., Studies on the quantitative and qualitative characterization of erythrocyte glutathione peroxidase. Journal Lab. Clin Mod. 70,158-169 (1967).

21. Klamt, F., Gottfried, C., Tramontina, F., Dal-Pizzol, F., Frota, J. Moreira, J.C.F., Dias, R.D., Moriguchi, E., Wofchuk, S. and Souza, D.O., Time-related increase in mitochondrial superoxide production, biomolecule damage and antioxidant enzyme activities in cortical astrocyte cultures. Neuro Report, 13,1515-1518 (2002).

22. Aebi, H. "Catalase in methods of Enzymatic Analysis" (Bergmeyer HU, Ed), 2, 673-678 Chemic. Academic Press. Inc. Verlag (1984).

23. Mazeron, P., Didelon, J., Muller, S., Stoltz, J., A theoretical approach of the measurement of osmotic fragility of erythrocytes by optical transmission. Photochem. Photobiol. 72, 172-178 (2000).

24. Banik, S., Bandyopadhyay, S. and Ganguly, S., Bioeffects of microwave-a brief review. Bioresour. Technol. 87, 155-159 (2003).

25. Belyaev, I.Y., Hillert, L., Protopopova, M., Tamm, C., Malmgren, L.O., Persson, B.R.R. Selivanova, G. and Harms-Ringdahl, M., $915 \mathrm{MHz}$ microwaves and $50 \mathrm{~Hz}$ magnetic field affect chromatin conformation and 53BP1 foci in human lymphocytes from hypersensitive and healthy persons. Bioelectromagnetics, 26,173-184 (2005).

26. Lai, H., Biological effects of radiofrequency electromagnetic field. In. "Encyclopedia of Biomaterials and Biomedical Engineering". wnek C.E., Bowlin, G.L., Ed. New York, NY: Marcel Decker 1-8 (2005). 
27. Stopczyk, D., Gnitecki, W., Buczynski, A., Markuszewski, L. and Buczynski, J., Effect of electromagnetic field produced by mobile phones on the activity of superoxide dismutase (SOD-1) and the level of malonyldialdehyde (MDA) - in vitro study. Med. Pr. 53, 311-314 (2002).

28. Zmyślony, M., Politanski, P., Rajkowska, E., Szymczak, W. and Jajte, J., Acute exposure to $930 \mathrm{MHz} \mathrm{CW}$ electromagnetic radiation in vitro affects reactive oxygen species level in rat lymphocytes treated by iron ions. Bioelectromag. 25, 324-328 (2004).

29. Oktem, F., Ozguner, F., Mollaoglu, H., Koyu, A. and Uz, E., Oxidative damage in the kidney induced by $900-\mathrm{MHz}$-emitted mobile phone: protection by melatonin. Archives of Medical Research 36, 350-355 (2005).

30.Yurekli, A.I., Ozkan, M., Kalkan, T., Saybasili, H., Tuncel, H., Atukeren, P., Gumustas, K. and Seker, S., GSM base station electromagnetic radiation and oxidative stress in rats. Electromag. Biol.Med. 25, 177-188 (2006).

31. Sokolovic, D., Djindjic, B., Nikolic, J., Bjelakovic, G., Pavlovic, D., Kocic, G., Krstic, D., Cvetkovic, T. and Pavlovic, V., Melatonin reduces oxidative stress induced by chronic exposure of microwave radiation from mobile phones in rat brain. J. Radiat. Res. 49, 579-86 (2008).

32.Vander Vorst, A., Rosen, A. and Kotsuka, Y. "RF/Microwave Interaction with Biological Tissues”. John Wiley \& Sons Inc. Hoboken, N.J. pp. 2-3 (2006).

33. Simko, M., Hartwig, C., Lantow, M., Lupke, M., Mattsson, M.O., Rahman, Q. and Rollwitz, J., Hsp70 expression and free radical release after exposure to non-thermal radio-frequency electromagnetic fields and ultrafine particles in human Mono Mac 6 cells. Toxicol. Lett. 161, 73-82 (2006).

34. Barcelo-Coblijn, G., Murphy, E.J. et al., Flaxseed oil and fish oil capsules consumption alters human red blood cell n-3 fatty acid composition: A multiple- Dosing trial comparing 2 sources of n-3 fatty acid. American Journal of Clinical Nutrition, 88(3), 801-809. (2008)

35. Galan, P., Kesse-Guyot, E., Czernichow, S., Briancon, S., Blacher, J. and Hercberg, S.SU., FOL.OM3 Collaborative Group. Effects of B vitamins and omega 3 fatty acids on cardiovascular diseases: a randomised placebo controlled trial. BMJ. 3416273 (2010).

36. Buhr, G. and Bales, C.W., Nutritional supplements for older adults: review and recommendations, part II. J. Nutr. Elder. 29 (1), $42-71$ (2010).

37. Savopol, T., Moraru, R., Dinu, A., Kovacs, E. and Sajin, G., Time course of the interaction of low level $2.45 \mathrm{GHz}$ radiation with the erythrocyte membrane. Bioelectrochemistry and Bioenergetics 40,171-173 (1996).

38. Schon, W., Ziegler, C., Gartner, H. and Kraft, G., Heavy ion induced membrane damage: hemolysis of erythrocytes and changes in erythrocyte membrane fluidity. Radiat. Environ. Biophys. 33, 253-241 (1994).

39. Kuchel, P.W. Coy, A. and Stibs, P., NMR "diffusion- diffraction" of water revealing alignment of erythrocytes in a magnetic field and their dimensions and membrane transport characteristics. Magnetic Resonance in Medicine, 37, 637-643 (1997).

Egypt. J. Biophys. Biomed. Engng. Vol. 12 (2011) 
40. Ali, F.M., Mohamed, S. and Mohamed, M., Effect of $50 \mathrm{~Hz}, 0.2 \mathrm{mT}$ magnetic field on $\mathrm{RBC}$ properties and heart function of albino rats. Bioelectomag. 24, 535-545 (2003).

41. Aiguo, W.u., Zhe,Yang and Fernando, Gomez-Pinilla, The Salutary Effects of DHA Dietary Supplementation on Cognition, Neuroplasticity, and Membrane Homeostasis after Brain Trauma, Journal of Neurotrauma. 28 (10), 2113-2122. doi: 10. 1089/ neu. 2011. $1872(2011)$

(Received 11/9/2012;

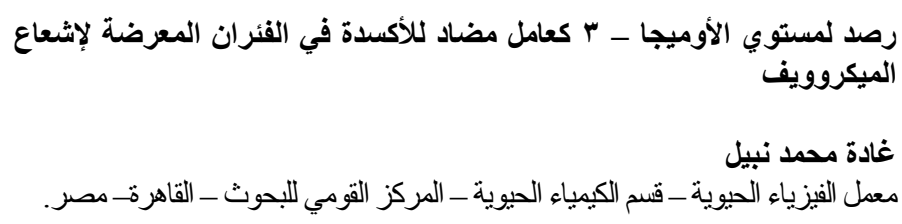

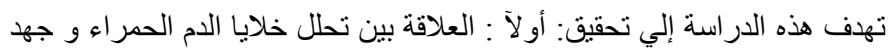

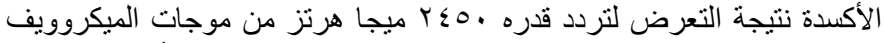

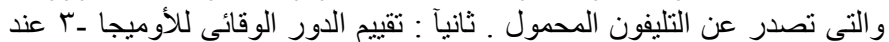

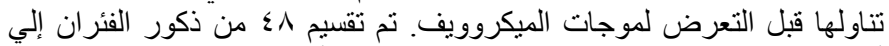

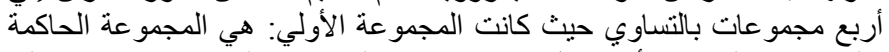

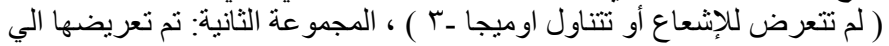

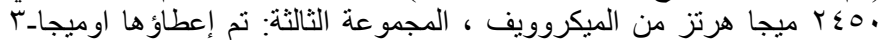

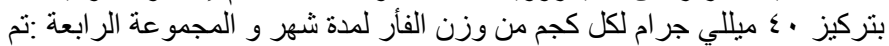

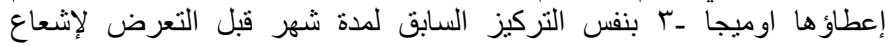

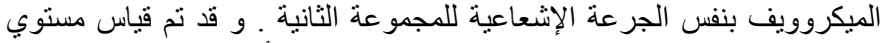

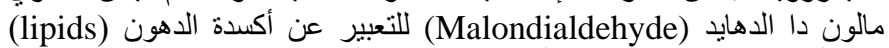

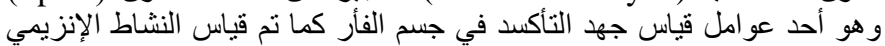

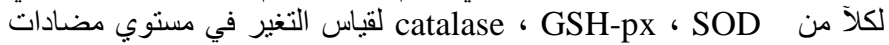

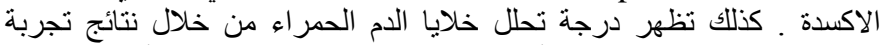

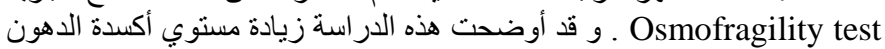

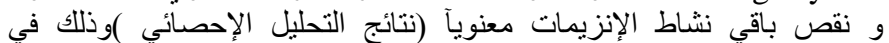

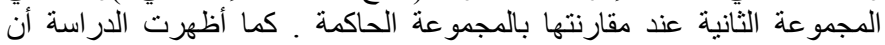

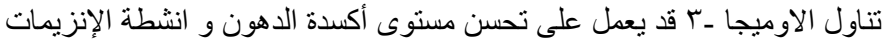

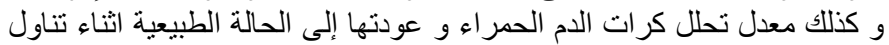

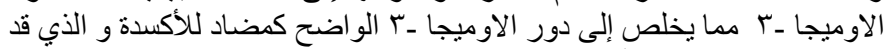

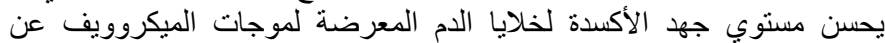

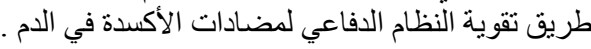

